\title{
Bánez frente a Suárez acerca de la libertad
}

\author{
Báñez versus Suárez about freedom \\ David Torrijos Castrillejo \\ Universidad San Dámaso, España \\ dtorrijos@sandamaso.es
}

DOI: https://doi.org/10.15366/bp2021.26.009 Bajo Palabra. II Época. No26. Pgs: 179-200 
Recibido: 15-07-2020

Aceptado: 20-08-2020

\section{Resumen}

En varias ocasiones, Bánez consideró a Suárez el principal promotor de la doctrina molinista junto al propio Molina. Según Báñez, el principal error del molinismo reside en una mala comprensión de la libertad. Esto le llevó a perfilar su teoría tomista de la libertad, según la cual el libre albedrío está radicalmente en el entendimiento y formalmente en la voluntad. El entendimiento es la raíz porque la indiferencia más importante se encuentra en el objeto, cuya conexión con el fin aparece como no necesaria. El entendimiento que capta esto origina una volición formalmente libre que no es incompatible con la eficaz moción divina.

Palabras clave: determinismo, libre albedrí, molinismo, tomismo, contingencia.

\section{Abstract}

On several occasions, Báñez considered Suárez the main supporter of the Molinist doctrine along with Molina himself. According to Báñez, the main mistake of Molinism is its misunderstanding of freedom. This led him to refine his personal Thomistic theory of freedom. Free will is radically in the intellect and formally in the will. Intellect is the root of freedom because the most important indifference is found in the object, whose connection with the end is understood as not necessary. The intellect aware of this indifference causes a formally free volition that is not incompatible with the effective divine motion.

Keywords: determinism, free will, Molinism, Thomism, contingency. 
El eminente dominico español Domingo BáŃez es conocido, principalmente, por dos razones: por su gran influencia sobre santa Teresa de Jesús y por protagonizar la disputa de auxiliis, donde se trató la vinculación entre la libertad humana y la omnipotencia divina. Este artículo va a fijarse en esta segunda faceta del teólogo. La postura de Báńez en dicho debate ha hecho que pasara a la historia como el

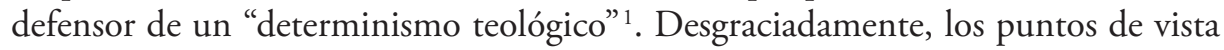
de Báńez sobre esa disputa no han sido demasiado estudiados, sobre todo en comparación con la incesante atención que recibe el molinismo. Aun menos han sido atendidas, pues, sus ideas sobre el libre albedrío ${ }^{2}$. Sin embargo, su forma de entender la libertad encierra gran interés y puede suavizar esa visión un tanto unilateral que a veces se tiene de él.

Bánez compuso un extenso comentario a la primera parte de la Suma de teología de santo Tomás ${ }^{3}$. Sus comentarios al Aquinate han sido calificados por Beltrán de Heredia como los mejores de la historia, sólo precedidos de los de Cayetano y Francisco de Vitoria ${ }^{4}$. Ese comentario alcanza también a la cuestión 83 sobre el libre albedrío, que, por fortuna, ha sido traducida a nuestra lengua ${ }^{5}$. En estas páginas no voy a centrarme exclusivamente en esta obra, publicada por primera vez entre 1584 y 1588 , sino que voy a tener en cuenta también otros escritos que fueron elaborados en el calor de la antes referida controversia teológica. En efecto, diez años después,

\footnotetext{
1 Véase, por ejemplo, Hasker, W., Providence, Evil and the Openness of God, London/New York, Routledge, 2004, p. 110.

2 Sobre este tema, se debe consultar la monografía de Matava, R. J., Divine Causality and Human Free Choice. Domingo Báñez, Physical Premotion and the Controversy De Auxiliis revisited, Boston, Brill, 2016, pp. 73-101. Véase también, Cai, Y., "The Efficacy of Grace according to Domingo Bañez", Augustiniana, 62 (2012), pp. 319-325.

${ }^{3}$ Báñez, D., Scholastica Commentaria in Primam Partem Angelici Doctoris D. Thomae Aquinatis usque ad sexagesimam quartam Quaestionem complectentia, Romae, J. Ruffinellus, 1584; Báñez, D., Super Primam Partem divi Thomae à Quaestione Sexagesimaquinta usque in finem Commentariorum, Salmanticae, S. Stephanus, 1588. En adelante citaré esta obra con la abreviatura In S. Th., indicando el artículo comentado de la Summa y me referiré a las columnas de acuerdo con la numeración de estos dos volúmenes, que constituyen la primera edición de ambas partes del comentario.

4 “[...] en cuya producción literaria, además de estar asimilados los valores principales de la generación anterior [de miembros de la Escuela de Salamanca], se advierte el sello personalísimo de su talento privilegiado, del mejor comentarista quizá que ha tenido Santo Tomás después de Cayetano y de Vitoria" (Beltrán de Heredia, V., "Valor doctrinal de las lecturas de Báńez”, en Miscelánea Beltrán de Heredia, vol. 3, Salamanca, OPE, 1972, p. 142).

5 Cf. Báńez, D., Tratado sobre el hombre. Comentario a Suma Teológica, I, qq. 80-83, García Cuadrado, J. Á. (introducción y notas); Gallego Salvadores, J. J.; García Cuadrado, J. Á. (trad.), vol. 3, Pamplona, EUNSA, 2015, pp. 205-251.
} 
en 1594, escribía que todos los errores de sus adversarios nacieron "de no entender la definición verdadera del libre albedrío y del acto libre" ${ }^{6}$. Estas palabras están recogidas en un memorial en romance escrito para defenderse de las acusaciones que hacía Suárez a los dominicos en un opúsculo, también en lengua vulgar, que se había hecho popular en Salamanca. Escribió esas páginas sin saber el nombre del autor e incluso en ellas manifestaba poco interés por Suárez, pese a haber oído de sus hermanos que sostenía ideas molinistas ${ }^{7}$. Sin embargo, enseguida se hace cargo de la influencia de este teólogo en la Compañía y lo menciona expresamente en la Apología, compuesta por los dominicos — con Báńez al frente- al año siguiente, para defender su postura y censurar el célebre libro de Molina ${ }^{8}$. Se trata de una amplia y elaborada obra que se ha mantenido inédita hasta el siglo pasado y, felizmente, también ha sido traducida al español ${ }^{9}$. Por último, el escrito más sugestivo de cuantos mencionamos aquí es el Tratado sobre la verdadera concordia, comenzado a escribir seguramente en 1594 pero rematado en 1600, de modo que en él se da respuesta incluso a algunas argumentaciones de Suárez publicadas en sus célebres Opuscula de $1599^{10}$.

El indudable prestigio de que goza hoy en día Francisco Suárez hace especialmente atractivo indagar cómo planteó su argumentación su principal adversario contemporáneo, Domingo Bánez. Es significativo que el principal problema que el teólogo dominico encuentra en la doctrina molinista no radica en su concepción de la acción divina sino sobre todo en cómo entiende la libertad. De este modo, esta controversia entre ambos colosos del pensamiento no se remonta tan sólo a grandes alturas metafísicas, sino que también apunta a la cuestión bien antropológica y humanista de la libertad.

En nuestras páginas, vamos a ocuparnos primero de la réplica de Báñez a Suárez en 1594, pues se trata —en palabras de García Cuadrado - de "un documento

\footnotetext{
${ }^{6}$ Báńez, D., "Réplica del padre Báńez al memorial difundido por el padre Suárez En defensa de la Compañia cerca del libre albedrío", en Beltrán de Heredia, V., Domingo Bánez y las controversias sobre la gracia: Textos y documentos, Madrid, CSIC, 1968, p. 443. En adelante, citaré este documento sencillamente como Respuesta.

7 Cf. Báñez, D., Respuesta, p. 432.

${ }^{8}$ Las páginas dedicadas a refutar el opúsculo de Suárez se encuentran en Báńez, D., "Apologia fratrum praedicatorum adversus quasdam assertiones cuiusdam doctoris Ludovici Molinae nuncupati”, III, cap. 1-2, en Beltrán de Heredia, V., Domingo Bánez y las controversias sobre la gracia, op. cit., pp. 271-282. En adelante, me referiré a esta obra sencillamente como Apologia.

9 Báńez, D., Apología de los hermanos dominicos contra la Concordia de Luis de Molina, Hevia Echevarría, J. A. (trad., introducción y notas), Oviedo, Pentalfa, 2002.

${ }^{10}$ Cf. Bánez, D., "Tractatus de vera et legitima concordia liberi arbitrii creati cum auxiliis gratiae Dei efficaciter moventis humanam voluntatem", en Báńez, D., Comentarios inéditos a la Prima secundae de santo Tomás, Beltrán de Heredia, V. (ed.), vol. 3, Madrid, CSIC, 1948, pp. 351-420. En adelante, me referiré a esta obra sencillamente como Tractatus.
} 
poco estudiado y que puede dar luz tanto sobre la doctrina suareciana como sobre la de Báńez" ${ }^{11}$. En segundo lugar, trataremos del Tratado sobre la verdadera concordia de 1600, donde veremos las contrarréplicas a las nuevas objeciones de Suárez, que permitirán a Báńez acabar de afinar su discurso sobre la libertad.

\section{La respuesta de Báñez a Suárez de 1594}

En el ESCRITO DE I 594 CONTRA SuÁrez, al señalar una distorsionada noción de libertad como clave del error de sus oponentes, Báńez tiene en mente la definición del libre albedrío aportada por Molina en la Concordia. Como escribirá al año siguiente, "Francisco Suárez, de la Compañía de Jesús, defiende la misma definición [de Molina] en cierto manuscrito redactado en lengua vulgar, que circulaba por Salamanca de mano en mano y que fue denunciado a los Padres del Santo Oficio y entregado por algunos tomistas. El título de este escrito era En defensa de la Compañia cerca del libre albedrio" 12.

Tal como la formuló Molina, dicha definición sonaba así: "La libertad puede considerarse como opuesta a la necesidad de tal modo que se llama agente libre al que, puestos todos los requisitos para actuar, puede actuar y no actuar o hacer así una cosa como hacer también lo contrario" ${ }^{13}$. En el escrito de Suárez aparece una formulación parecida en romance: "[...] la esencia y naturaleza del acto libre está en que la potencia que le obra, teniendo todo lo necesario para poderle hacer, esté con todo eso indiferente e indeterminada para obrar o no" ${ }^{14}$. Por último, la definición es resumida por Báñez escribiendo en latín: "Liberum arbitrium est quod, positis omnibus requisitis ad agendum, potest agere et non agere" ${ }^{15}$. El teólogo no la encuentra del todo errónea, aunque no esté tomada de la tradición agustiniana y tomista. Es más, él mismo la llegó a emplear en alguna ocasión, como ha observado

${ }^{11}$ García Cuadrado, J. Á., Domingo Báñez (1528-1604): Introducción a su obra filosófica y teológica, Pamplona, Servicio de Publicaciones de la Universidad de Navarra, 1999, p. 55.

12 "Eamdem diffinitionem statuit Franciscus Suarez, ejusdem Societatis, in quodam manscripto quod vulgari sermone Salmanticae circumferebatur, et patribus Sancti Offici denuntiatum et traditum est a quibusdam thomistis. Huic scripto titulus erat, En defensa de la Compañia cerca del libre albedrio" (Báñez, D., Apologia, I, cap. 12, n. 1, p. 166; trad. esp., p. 93).

13 “[Libertas] accipi potest, ut opponitur necessitati: quo pacto illud agens liberum dicitur, quod positis ómnibus requisitis ad agendum, potest agere, \& non agere, aut ita agere unum, ut contrarium etiam agere possit" (Molina, L., Liberi arbitrii cum gratiae donis, divina praescientia, providentia, praedestinatione et reprobatione concordia, I, q. 14, a. 13, disp. 2, Olyssipone, Riberius, 1588, p. 12).

14 Suárez, F., "En defensa de la Compañía cerca del libre albedrío", en Beltrán de Heredia, V., Domingo Bánez y las controversias sobre la gracia, op. cit., p. 460.

15 Báñez, D., Respuesta, p. 446. 
Matava ${ }^{16}$. Ya la había hecho suya otro gran maestro de la Escuela de Salamanca, Domingo de Soto ${ }^{17}$. Nuestro teólogo la atribuye al nominalista Almaino —un autor bastante tenido en cuenta por Vitoria y sus discípulos-, el cual ciertamente la consignó en sus escritos ${ }^{18}$.

Para Báńez, esta definición no logra su propósito porque no da cumplida cuenta de la esencia del libre albedrío, aunque, en cuanto corolario que se sigue de ella, tampoco es enteramente falsa. Toda la malicia procede aquí de haberla entendido de una manera incorrecta. El problema se encuentra en la identificación de los "requisitos" requeridos para la acción libre, supuestos los cuales, todavía puede el albedrío obrar en un sentido u otro. Porque, si entre esos requisitos se encontrase, por ejemplo, el último juicio práctico que orienta la voluntad, no es posible que la voluntad disienta de él, una vez que el entendimiento presente una obra determinada para que sea realizada hic et nunc. Luego, no es "composible" que el entendimiento impere una obra circunstanciada y que la voluntad aún permanezca indiferente respecto de su inclinación (es decir, ambas cosas no pueden suceder a la vez). Y no cabe duda de que el último juicio práctico del entendimiento es un requisito de la libertad.

Como vemos, Báńez se sitúa en una postura netamente tomista, que no admite que la voluntad se mantenga indeterminada respecto del último juicio práctico del intelecto $^{19}$. ¿Dónde radica, pues, la libertad? La raíz de la libertad se encuentra en la "indiferencia" que nuestra inteligencia reconoce respecto de los bienes no irresistibles para la voluntad ${ }^{20}$. Todo bien finito representa un foco de interés para la voluntad y es capaz de atraer a ésta, con tal que el entendimiento sepa atender a la bondad sita en él. No obstante, cualquier bien finito, por serlo, atrae de manera limitada a la voluntad. Sólo un bien infinito la atraería de manera irresistible. En este sentido, todo bien finito es "indiferente": no en el sentido de atraer "poco" la voluntad, sino porque no la atrae con necesidad. Sólo Dios es apetecido de manera

16 Matava, R. J., Divine Causality and Human Free Choice, op. cit., p. 78, nota 120.

17 Cf. Soto, D., De natura et gratia, I, cap. 16, Venetiis, Iuntas, 1547, fol. 57r.

${ }^{18}$ Cf. Almainus, J., Moralia, cap. 1, Paris, Gaudoul, 1516, fol. 3v. Es atribuida a Almaino, sin dar ninguna referencia, en Báñez, D., Respuesta, p. 447; Apologia, I, cap. 12, n. 1, p. 166.

${ }^{19}$ No es exacta la posición de Matava al asignar a la voluntad la posibilidad de seguir o no el juicio del entendimiento: "[...] the will retains the ability to reject the judgment of reason" (Matava, R. J., Divine Causality and Human Free Choice, op. cit., p. 83). Báńez no otorga semejante libertad a la voluntad, que siempre sigue el juicio del entendimiento, por más que dicho juicio esté imperado a su vez por ella, como se ve claramente en el texto que estamos comentando: “[...] consta claramente que para la elección libre de la voluntad es necesario el dictamen del entendimiento, el cual puesto es imposible o por mejor decir incomposible que la voluntad no elija” (Báñez, D., Respuesta, p. 447). Explica esto con cierto detalle, por ejemplo, a propósito del pecado del ángel: cf. Bánez, D., In S. Th., I, q. 62, a. 3, col. 921A-923C.

${ }^{20}$ Cf. Báñez, D., In S.Th., I, q. 83, a. 1, col. 969A-976A. 
necesaria por la voluntad, con tal que se presente al entendimiento tal cual es, es decir, como bondad irrestricta. Esto hace que, para Bánez, la libertad se encuentre "radicalmente" en el entendimiento y "formalmente" en la voluntad. En efecto, es la voluntad quien se inclina de manera libre pero la raíz de la libertad de dicha inclinación está situada en la apreciación de la "indiferencia" del bien mostrado por el entendimiento. Así se había expresado ya en 1584:

El entendimiento propone a la voluntad un objeto que es de suyo indiferente para lograr el objeto de la voluntad y no posee una conexión necesaria con él; no obstante, juzga que es ordenable hacia el fin de la voluntad, o a la consecución de éste, o a participar de cierta bondad tomada del fin, y entonces juzga que ha de ser ordenado hacia el fin; enseguida, la voluntad elige y en tal elección es formalmente libre ${ }^{21}$.

Es la apreciación del entendimiento que capta la falta de conexión necesaria del medio respecto del fin la que constituye en libre el acto de la voluntad. Esto tiene gran importancia porque, igual que el entendimiento, aun determinado a una parte, provoca un acto libre en la voluntad, así también la moción divina, si bien inclina a la facultad creada hacia una volición concreta, no elimina la libertad humana:

De aquí se sigue que, aunque la divina moción que acompaña a la elección nuestra sea eficacísima, como quiera que no borre aquel juicio del conocimiento de la indiferencia del medio al objeto de la voluntad, no quita la libertad en la elección, antes la perficiona, por ser moción acompańada de luz divina que aclara el entendimiento para que mejor juzgue entre muchos medios lo que le conviene. $Y$ en esto consiste la fuerte y suave moción de la divina sabiduría, fuerte en ejecutar lo que esta en su divina providencia, y suave en ejecutarlo en cada cosa conforme a su naturaleza ${ }^{22}$. Y por ser el hombre hecho a semejanza de Dios por la razón y libre albedrío que tiene, muévele dando luz en el entendimiento e inclinación en la voluntad ${ }^{23}$.

La moción divina no es algo extraño al ser humano, que de algún modo desvirtuaría sus fuerzas, sino que las consolida: fortalece el entendimiento para apreciar mejor la bondad digna de ser escogida, de tal modo que la voluntad, si bien le sigue con eficacia, no sufre merma alguna, pues esa iluminación se acomoda a la dignidad racional de la persona humana. Por eso, igual que nadie pierde libertad por el hecho

\footnotetext{
21 "Proponit enim intellectus voluntati obiectum, quod de seipso indifferens est ad assecutionem obiecti voluntatis, neque cum illo necessaria connexionem habet, et nihilominus iudicat ordinabile esse ad finem voluntatis, vel ad assecutionem illius, vel ad participandum aliquam bonitatem ex fine, et tunc iudicat ut ordinetur ad finem, et tunc voluntas eligit, et in tali electione formaliter est libera" (Báńez, D., In S. Th., I, q. 19, a. 10, col. 381E-F).

${ }_{22}$ Cf. Sb 8,1.

${ }^{23}$ Báńez, D., Respuesta, p. 447.
} 
de estar decidido a hacer algo aquí y ahora y, sin embargo, mientras uno está decidido, "no puede" elegir otra cosa, así tampoco la moción divina arruina la libertad, por mucho que, si se da, no puede suceder, a la vez, que el hombre se incline en otro sentido. La moción divina tan sólo afianza la imagen de Dios que hay en el hombre, no la destruye: por eso la moción de Dios no hace menos libre al hombre sino que lo hace más libre, esto es, más semejante a Dios.

Aquí es donde entra la distinción escolástica entre "sentido compuesto" y "sentido dividido", que Bánez también denomina "sentido divino" 24 . Es una distinción que se emplea para expresar cómo ciertas proposiciones pueden predicarse de un sujeto. En principio, de un hombre se puede predicar, por ejemplo "estar en pie" o "estar sentado". Sin embargo, ambas se pueden decir sólo "en sentido dividido", es decir, como posibilidades. En cambio, si se afirman en "sentido compuesto", o sea, como si una de ellas se estuviera dando de hecho aquí y ahora en este sujeto, entonces sólo una es verdadera y la otra es necesariamente falsa, porque son mutuamente excluyentes. En consecuencia, de igual manera que Pedro es libre para estar en pie o sentado pero, si elige estar de pie, ya no puede estar sentado, así también, si Dios mueve a Pedro para que elija lo uno ya no puede elegir lo contrario, puesto que la moción de Dios es simultánea con la voluntad del hombre. En efecto, Bánez no entiende que Dios mueva a Pedro a pesar de su libertad sino que mueve su inteligencia y su voluntad para que aquí y ahora haga este acto libremente. La intervención divina no desnaturaliza la acción humana y tan sólo supone una necesidad lógica (sencundum quid necessarium), porque la volición creada continúa siendo absolutamente contingente (simpliciter contingens) ${ }^{25}$.

Naturalmente, la distinción entre sentido compuesto y dividido no resultaba suficientemente convincente a Molina y una argumentación como la que plantea aquí Bánez le resultaría aun así insatisfactoria. Por eso, nuestro teólogo sale al paso de la objeción que podrían plantear sus adversarios:

A esta forma podremos decir, cuando contra nosotros arguyen diciendo que, puesto el socorro eficaz de la divina gracia, no podemos dejar de obrar, y que así no quedamos libres en aquel consentimiento. A lo cual respondemos que, estando aquel auxilio eficaz, es incomposible que no obremos; pero no es incomposible que obrando tengamos potestad para no obrar, porque la potestad bien se compadece con el acto contrario al otro que está en potencia. Porque de otra suerte ninguna elección del hombre sería libre, pues que puesto el dictamen e imperio de la razón es incomposible que no elija; pero no es incomposible que

${ }^{24}$ Cf. Báńez, D., Respuesta, p. 448. Véase también Apologia, I, cap. 12, n. 2, pp. 167-168.

${ }^{25}$ Cf. Osborne, Th. M., "Thomist Premotion and Contemporary Philosophy of Religion", Nova et Vetera, English Edition, 4 (2006), pp. 617-621; Torrijos-Castrillejo, D., "Tomás de Vío, Cayetano: Sobre la providencia y el hado", Revista española de teología, 78 (2018), pp. 476-479. 
juntamente tenga potestad para no elegir. Antes cuando elije tiene conocimiento de la indiferencia del medio que escoje para el fin de la voluntad, el cual conocimiento es raiz primera de la elección libre de la voluntad, no obstante que el dictamen e imperio singular determine a la voluntad a uno. Y no vale decir que el dictamen que yo tengo e imperio es ab intrinseco, y que yo le puedo mudar. Lo primero porque ese propio dictamen e imperio también es efecto de Dios, que más intrínsecamente obra en mi que mi propia alma: In ipso enim vivimus, movemur et sumus ${ }^{26}$. Y así no podemos tener acto vital ni movimiento sin que Dios le obre en nosotros, porque es causa íntima de todo nuestro ser, sin dependencia de otra causa; pues él es omnipotente para hacer y conservar todo lo necesario para el efecto que pretende. Y así nuestro dictamen proviene eficacísimamente de la voluntad de Dios, que absolutamente quiere que agora yo escoja este bien en singular sin derogar a mi libre albedrío, antes perficionándole y moviéndole a su modo, como Dios de lo natural y de lo moral ${ }^{27}$.

Esta respuesta es muy interesante porque se exhibe algo que está en el fondo de la discusión: si Dios es el creador, no es enteramente ajeno a la criatura y su moción no es algo extraño a ella. Por este motivo, su moción no puede ser considerada antinatural o violenta. Primero, porque no fuerza a la voluntad en contra de lo que ella misma decide siguiendo al intelecto ${ }^{28}$. En palabras de Solana, "para que Dios violentara la libertad humana tendría que destruir previamente el juicio de indiferencia que respecto a un objeto formula el entendimiento; y que, por lo tanto, es imposible que Dios fuerce el libre albedrío y a la vez deje subsistente el juicio intelectual de indiferencia" ${ }^{29}$. Segundo, porque Dios es la causa más profunda del ser humano, todo se lo debe a Él, de modo que no interviene en el corazón humano como un intruso, sino como el autor de su naturaleza que le da auge y plenitud ${ }^{30}$. Como dijo Mateo-Seco, "sin la eficacia de la actuación divina sobre nuestra libertad [...] no puede tener lugar el actuar libre de nuestra voluntad, ya que nuestro libre actuar brota del actuar libre de Dios. [...] libertad divina y libertad humana no solo no se oponen, sino que la libertad divina es la fuente de la que brota el libre actuar humano" ${ }^{31}$.

Por otra parte, cuando, en el texto que acabamos de citar, decía que la raíz de la libertad es el "conocimiento de la indiferencia del medio que escoje para el fin de la voluntad", no se refiere necesariamente al fin último que de hecho es Dios, puesto

${ }^{26}$ Cf. Hch 17,28 .

27 Báñez, D., Respuesta, p. 449.

28 Cf. Báñez, D., In S. Th., I, q. 82, a. 1, col. 897B-898A.

29 Solana, M., Historia de la filosofía española. Época del Renacimiento. (siglo XVI), vol. 3, Madrid, Asociación Espańola para el Progreso de las Ciencias, 1940, p. 194.

30 Cf. Báńez, D., In S. Th., I, q. 82, a. 1, col. 911B-912B.

31 Mateo-Seco, L. F., “Providencia y libertad en D. Báńez”, en González-Ayesta, C. (ed.), El alma humana: esencia y destino. IV Centenario de Domingo Báñez (1528-1604), Pamplona, EUNSA, 2006, p. 192. 
que el hombre puede estar inclinado hacia un falso fin último ${ }^{32}$. Lo principal aquí es que el entendimiento advierta la indiferencia de los medios respecto del fin perseguido en cada momento. Ello basta para garantizar la libertad.

Así, pues, para que la definición de libertad no excluya desde el inicio el auxilio divino, Báñez cree que se debe escoger otra definición. No le sirve tampoco la aportada por Belarmino, porque no es lo suficientemente formal como para abarcar tanto a Dios como a las criaturas ${ }^{33}$. De tal modo, él mismo propone su propia definición:

Liberum arbitrium est facultas intellectus et voluntatis ad agendum vel non agendum, vel ad prosequendum unum vel aliud.

El libre albedrío es la facultad del entendimiento y de la voluntad para obrar o no obrar, o bien para obrar una cosa u otra ${ }^{34}$.

Cree que esta definición es del todo "formal", pues excluye incluso la referencia a la ratio que tenía la del maestro de las Sentencias. Así no hay ningún obstáculo para aplicarla incluso a Dios. Pero, lo más importante para la cuestión de la relación entre la libertad y la intervención divina es que esta definición no exige la posibilidad de pecar, pues, como ya había explicado santo Tomás, "querer el mal no es ni libertad ni parte de la libertad", sino tan sólo "cierto signo" de ella ${ }^{35}$. Por eso, el libre albedrío confirmado en el bien — como el de los ángeles bienaventurados, el del hombre Jesús o la Virgen María y el de Dios mismo - no es menos libre por no poder pecar, sino incluso más, puesto que la posesión del bien sumo los hace mejor dispuestos para escoger con soberanía respecto de los bienes inferiores ${ }^{36}$. Por este motivo, el corazón del libre albedrío, tal como se declara en la definición de Báñez, se advierte al

\footnotetext{
32 Cf. Báńez, D., Respuesta, p. 457.

33 Cf. Báñez, D., Respuesta, p. 450; Apologia, I, cap. 13, n. 1, p. 169. He aquí su definición: "Liberum arbitrium est libera potestas ex his, quae ad finem aliquem conducunt unum prae alio eligendi, aut unum et idem acceptandi, vel pro arbitrio respuendi, intelligenti naturae ad magnam Dei gloriam attributa" (Bellarminus, R. Controversia de gratia et libero arbitrio, 1. 3, cap. 3, en Opera omnia, vol. 5, Paris, Vivès, 1873, p. 583).

34 Báñez, D., Respuesta, p. 453.

35 "[...] velle malum nec est libertas, nec pars libertatis, quamvis sit quoddam libertatis signum" (De ver, q. 22, a. 6, in c.). Cf. S. Th., I, q. 62, a. 8, ad 3; II-II, q. 88, a. 4, ad 1; I Sent., d. 42, q. 2, a. 1, ad 3. Báñez comenta el primero de estos pasajes de la Summa con estas palabras: "Notanda est valde solutio ad tertium, ubi D. Thomas docet, perfectam rationem libertatis non consistere in hoc, quod eligat opposita divertendo ab ordine finis; nam hoc potius est defectus libertatis; sed libertas arbitrii consistit in hoc, quod possit diversa eligere, servato ordine ad finem. Unde maior libertas arbitrii est in beatis, qui a fine ultimo peccando declinare non possunt, quam in nobis viatoribus, qui peccare possumus" (In S. Th., I, q. 62, a. 8, col. 908D).

36 Cf. Báńez, D., Respuesta, pp. 454-455; Báńez, D., Apologia, I, cap. 13, nn. 3.6, pp. 171.172.
} 
percibir en qué consiste formalmente la indiferencia de poder querer un medio y poder no quererlo, y querer una cosa o otra indiferentemente. Y digo que la principal raiz y fundamento desta indiferencia nace de que el entendimiento juzga la indiferencia que hay en el medio respecto del fin. De aquí es que esta indiferencia no es necesaria que se sujete en el propio entendimiento o en la voluntad que ha de escoger, porque si esto fuese verdad, no podría haber en Dios libre albedrío, apud quem non est transmutatio nec vicisitudinis obumbratio $^{37}$, por ser Dios acto puro como arriba dijimos, y ser imposible haberse en sí mismo de otra manera de como eternalmente es que sea. Luego basta para la libertad de la voluntad que el entendimiento juzgue y proponga la indiferencia de los medios al fin ${ }^{38}$.

La idea es sutil: la raíz de la libertad no se encuentra en la indiferencia e inestabilidad del entendimiento o de la voluntad sino más bien en el juicio sobre la indiferencia respecto de los bienes finitos. Es decir, lo crucial es apreciar el carácter de no irresistibles de tales bienes. La voluntad divina es un punto de comparación crucial, pues está inmutablemente establecida incluso respecto de sus decisiones contingentes; no obstante, su libertad no radica en una mutabilidad que no tiene, sino más bien en el juicio sobre la incapacidad de los bienes finitos para atraerla de modo necesario. Igual sucede con nuestra voluntad, que sí puede cambiar, pero no es más libre por esos cambios, sino por el juicio previo del entendimiento acerca de la indiferencia de los bienes finitos alcanzados por nuestras elecciones. Por eso, los elementos antecedentes o concomitantes de semejantes voliciones no pueden en modo alguno ahogar la libertad presente en ellas. Por supuesto, tampoco la intervención divina.

De acuerdo con este núcleo teórico de su definición, también da por buena esta otra: "El agente libre es aquel que obra por un fin con conocimiento de la indiferencia de los medios al fin" ${ }^{39}$. Por tanto, quien obra así manifiesta la semejanza divina puesta en él, de modo que la moción divina tan sólo viene a corroborar dicha semejanza y "no por eso [la criatura] deja de ir con perfecta libertad, pues no le quitan aquel juicio universal en que se juzga la indiferencia del medio al fin, antes va caminando con miedo de que es posible cesar del amor de Dios o faltar a su ley por la potestad que en sí siente antes de conseguir el último fin, que es ver a Dios. Donde ya la voluntad no quedará con libertad para poder dejar de amar a Dios, porque la vista clara de Dios le descubre estar en Él todos los bienes juntos en un sumo y infinito bien, y así ya no puede tener aquel juicio de que le puede convenir querer algún bien fuera de Dios. Pero aun entonces queda libre para amar a las criaturas

\footnotetext{
37 St 1,17 .

38 Báñez, D., Respuesta, p. 455. Cf. Báńez, D., Apologia, I, cap. 13, nn. 5-6, p. 172.

39 "Agens liberum est quod operatur propter finem cum cognitione indifferentiae mediorum ad finem" (Báñez, D., Respuesta, p. 456). Cf. Báńez, D., Apologia, I, cap. 13, n. 7, p. 173.
} 
conocidas en su propia especie, enderezando este amor a Dios, porque tampoco el precepto divino borra el juicio de la indiferencia que aquel medio de suyo tenía para alcanzar a gozar del último fin" ${ }^{40}$. Estar consolidada en la gracia y el amor de Dios no obsta para la libertad de la criatura, porque es precisamente un mejor conocimiento de Dios, su último fin, aquel que asegura el desprendimiento de la criatura respecto de los bienes finitos y su carácter de subordinados al bien supremo. Por eso, tampoco la posesión del fin último impide que la criatura racional pueda relacionarse con otras criaturas teniéndolas como participaciones de la bondad suma.

\section{La respuesta de Báñez a Suárez de 1600}

En LAS NOTAS AL PIE DE LAS PÁgINAS PRECEDENTES hemos ido mostrando algunos pasajes de la Apologia de 1595 paralelos al memorial en español de Bánez escrito en 1594. Se trata precisamente de los lugares de la Apologia donde se habla de la libertad de modo temático. La coincidencia entre ambos documentos no es sorprendente porque los dominicos declararon que el segundo se compuso a partir de los tratados en que distintos teólogos de dicha Orden manifestaban su posición respecto de la controversia y del libro de Molina en particular ${ }^{41}$. Entre estos opúsculos se encontraba uno de Báńez, que debía de consistir en una primera redacción del Tratado sobre la verdadera concordia, al que aludió como un "tratado en latín" sobre estas cuestiones, que andaba por entonces componiendo ${ }^{42}$. Sin duda, esta obra debía de tener fuertes similitudes con el memorial en español de 1594, como las tiene la versión de 1600 que ha llegado hasta nosotros. En efecto, se podría construir una sinopsis en tres columnas con muchos pasajes de la Respuesta, la Apologia y el Tratado. Sin embargo, mi propósito aquí no es mostrar las coincidencias, sino sobre todo la aportación de la versión definitiva del Tratado que tenemos en nuestro poder.

Como hemos adelantado antes, el aspecto más atrayente de esta obra es que tiene en cuenta también los Opuscula de Suárez de 1599. Es cierto que en ese libro Suárez continúa sosteniendo sustancialmente idénticas posiciones. Con todo, la estrategia defensiva de la Compañía durante las Congregaciones de auxiliis, que estaban teniendo lugar en Roma desde 1597, fue presentar antes de nada la enseñanza congruista, que suavizaba los aspectos más controvertidos del molinismo ${ }^{43}$. Esto se

\footnotetext{
${ }^{40}$ Báñez, D., Respuesta, p. 456.

${ }^{41}$ Cf. Beltrán de Heredia, V., Domingo Báñez y las controversias sobre la gracia, op. cit., pp. 92-93.

42 Cf. ibid., p. 90.

43 Al hablar de "estrategia" no quiero acusar a la Compañía de maquiavelismo, sino sólo me hago eco de cuanto afirma el historiador jesuita Scorraille, R. de, El P. Francisco Suárez, de la Compañía de Jesús, vol. 1, Barcelona,
} 
hace sentir en el pensamiento de Suárez, si bien la crítica más aguda del congruismo llevada a cabo por Báñez se encuentra, en mi opinión, en unas páginas que escribió respondiendo a los jesuitas comisionados en la Congregación de auxiliis en Roma ${ }^{44}$. El Tratado sobre la verdadera concordia tiene la ventaja de ser más sistemático y en él vuelven a aparecer las explicaciones sobre el libre albedrío que ya conocemos, pero en su discurso se van enhebrando algunas réplicas al reciente libro de Suárez.

La primera parte del Tratado está íntegramente dedicada a la cuestión de la libertad. En el primer capítulo, después de quejarse nuevamente de la definición de Molina y de citar por primera vez los Opuscula para mostrar que, según Suárez, la eficacia completa de la gracia dependería, al fin y al cabo, de nuestro libre albedrío, enseguida vuelve a arremeter contra él, convirtiéndolo — cada vez más a las clarasen el verdadero interlocutor de la disputa ${ }^{45}$. Según Báńez, Suárez parece acusar a los Padres Predicadores de entender el libre albedrío como si tuviera tan sólo una indiferencia pasiva ${ }^{46}$. Por este motivo, el Tratado retomará el tema de la indiferencia para mostrar su relación con la esencia más íntima del libre albedrío.

El Tratado va a repasar buena parte de las ideas que aparecían en las obras que ya conocemos pero, en lo tocante al tema de la libertad, va a ser más fino y a incorporar nuevas reflexiones. En primer lugar, aparece otra vez la definición del libre albedrío propuesta por Báńez: la formulada tanto en la Respuesta de 1594 como en la Apologia de 1595. Sin embargo, aquí se añade "la definición exacta del libre albedrío de acuerdo con su íntegra razón universal" que consistiría en "una facultad del entendimiento y de la voluntad abierta a cualquiera de dos posibilidades" ${ }^{47}$. Insiste en que esta apertura del libre albedrío no incluye de suyo el pecado. La apertura deriva de la imperfección sita en los bienes finitos hacia los cuales un ente intelectivo puede inclinarse. Esto ayuda a apreciar mejor la "indiferencia" vinculada al libre albedrío, de modo que Bánez puede extraer el siguiente corolario: "[...] aunque las

Subirana, 1917, pp. 440-446. Para una visión sintética del congruismo: cf. Craig, W. L., The Problem of Divine Foreknowledge and Future Contingents from Aristotle to Suarez, Leiden, Brill, 1988, pp. 226-229; Matava, R. J., "A Sketch of the Controversy de auxiliis", Journal of Jesuit Studies, 7 (2020), pp. 431-432.

${ }_{44}$ Me refiero a Báñez, D., "De efficacia praevenientis auxilii gratiae, an sit intrinsece et a se, vel a libero hominis arbitrio. Disputatio inter patres Societatis Jesu et magistrum Bañes: circa annum 1599-1600”, en Beltrán de Heredia, V., Domingo Báñez y las controversias sobre la gracia, op. cit., pp. 613-638. Creo que este texto data probablemente de 1599, cuando debió de escribir una réplica a las respuestas de los jesuitas a las preguntas formuladas por el Cardenal Madruzzo. Dichas respuestas fueron impresas ya por Serry, J. J. [Le Blanc, A.], Historiae congregationum de auxiliis divinae gratiae, sub Summis Pontificibus Clemente VIII et Paulo V, Lovanii, Aegidium Denique, 1700, Appendix, col. 95-100.

${ }^{45}$ Cf. Báńez, D., Tractatus, I, cap. 1, nn. 5-6, p. 358. Véase Suárez, F., Opuscula, vol. 11, Opera omnia, III, cap. 6, n. 7, Paris, Vivès, 1858, p. 180.

${ }^{46}$ Cf. Suárez, F., Opuscula, op. cit., I, cap. 2, n. 2.

47 "Verumtamen exacta definitio liberi arbitrii secundum totam suam universalem rationem est, quod sit facultas intellectus et voluntatis ad utrumlibet” (Báñez, D., Tractatus, I, cap. 1, n. 8, p. 360). 
cosas indiferentes sean necesarias para la razón de libre albedrío, sin embargo no por ello será más perfecto el libre albedrío por ser indiferente de muchos modos distintos" ${ }^{48}$. La multiplicación de objetos indiferentes capaces de atraer al libre albedrío no aumenta su libertad: de lo contrario, habría que admitir que el pecador tiene más libertad que el confirmado en gracia, el cual jamás estaría dispuesto a barajar entre los medios en vistas de su fin algo que lo aparte de la ley divina. En otras palabras, poder obrar el mal no aporta nada a la libertad.

Tal importancia adquiere la cuestión de la "indiferencia" en este nuevo tratamiento del libre albedrío, que se convierte en protagonista del segundo capítulo de la primera parte del Tratado ${ }^{49}$. Volviendo sobre las razones que ya se habían expuesto en los escritos anteriores, se concluye que la indiferencia propia del libre albedrío es "negativa", no "privativa": es decir, no es preciso que no esté de hecho determinado hacia una decisión, sino que no lo esté por naturaleza. Porque, por ejemplo, Dios está eternamente inclinado hacia los bienes contingentes que, de hecho, su libre albedrío ha escogido y, no porque estas decisiones estén tomadas, son menos libres. Basta que no esté inclinado a ellas por naturaleza. En cambio, la indiferencia privativa sería, por ejemplo, la que posee uno antes de irse de vacaciones, cuando aún no ha escogido su destino. Además, la indiferencia del libre albedrío es activa, puesto que es él mismo quien se inclina a sí propio.

En el capítulo de los Opuscula de Suárez mentado por Bánez, donde el jesuita habría acusado presuntamente a los dominicos de defender una indiferencia tan sólo pasiva, es reprobada una teoría de la libertad que parece aproximarse bastante a la réplica de Báñez en su obrita de 1594 y en la Apologia. Suárez se refiere a ciertos "teólogos recientes" que "constituyen la libertad de la voluntad en la mera indiferencia - como dicen - del juicio de la razón: no que el juicio de la razón sea formalmente indiferente, sino que mediante él se juzgue la indiferencia que el objeto o medio posee respecto de la voluntad o fin. Por tanto, ésta puede resumirse en una palabra como indiferencia objetiva" ${ }^{50}$. Curiosamente, esta doctrina se parece mucho a la que Bánez, en su comentario a la Summa, atribuyó a Durando para disentir de ella, ya que — como hemos visto— la libertad de arbitrio se halla

48 "[...] quamvis indifferntia sit necessaria ad rationem liberi arbitrii, tamen non ideo erit perfectius liberum arbitrium quia pluribus modis in se est indifferens" (ibid., n. 9, p. 362).

${ }^{49} \mathrm{La}$ indiferencia del juicio del intelecto había sido el tema de un dubium en los comentarios a la Summa: cf. Báńez, D., In S.Th., I, q. 83, a. 1, col. 969A-976A. En todo caso, aquí se precisa la postura frente a las nuevas objeciones de los oponentes.

50 "Altera sententia est quorumdam recentiorum Theologorum, qui libertatem voluntatis constituunt in sola indifferentia (ut aiunt) judicii rationis, non quod ipsum rationis judicium formaliter indifferens sit, sed quod per ipsum judicetur indifferentia quam objectum vel medium habet respectu voluntatis vel finis. Unde uno verbo dici potest haec indifferentia, objectiva" (Suárez, F., Opuscula, op. cit., I, cap. 2, n. 5, p. 9). 
formalmente en la voluntad y sólo radicalmente en el juicio del entendimiento ${ }^{51}$. Es más, Suárez, en el mismo pasaje, emplea esa misma distinción, atribuyéndola a los "teólogos más peritos", con el propósito de refutar la teoría de la "indiferencia objetiva" 52: iparece estar atacando a Báńez con argumentos del propio Báńez! En cualquier caso, el teólogo dominico se sintió acusado por estas páginas pues, al final del capítulo tercero, afirma: "[...] estamos lejos de aquella sentencia que Suárez nos atribuye, de acuerdo con la cual la razón de la libertad y su uso consistiría formalmente en el conocimiento y el juicio de indiferencia del objeto" ${ }^{53}$. Y al punto recuerda que dicho juicio constituye la raiz pero no la formalidad del libre arbitrio, la cual se sitúa en la voluntad.

En consecuencia, la conclusión cuarta del capítulo segundo de la primera parte del Tratado sobre la verdadera concordia podría ser entendida como una respuesta a esta objeción de Suárez, según vamos a ver. Pero antes es preciso fijarnos en la conclusión tercera, que Báñez refiere de este modo: "En todo libre albedrío creado se encuentra no sólo una indiferencia pasiva del objeto conocido en cuanto elegible de modo indiferente, sino que también se encuentra cierta indiferencia pasiva con cierta potencialidad del sujeto" ${ }^{54}$. Es decir, aunque haya una indiferencia en el objeto, debido a su capacidad de atraer la voluntad de un modo no irresistible, también hay una indiferencia en el sujeto, si es creado. La indiferencia del objeto es pasiva para el sujeto, porque el carácter finito que hace indiferente al objeto no es determinado por el sujeto, sino que se debe a la índole del objeto mismo. Pero Bánez admite también una indiferencia pasiva en el sujeto creado, es decir, el sujeto no es puramente activo, sino que su actividad es en él recibida. No sólo posee su fuente de actividad en relación con el ser recibido de Dios por creación y conservación, sino que, incluso en su ejercicio, depende de Dios en cuanto primer moviente de sus actos. Asimismo, es preciso que haya cierta pasividad en el sujeto para que la criatura sea susceptible de provocar un acto inmanente, el cual supone una cierta mutación, un cambio. Todo lo contrario sucede en Dios para quien las decisiones de su libre albedrío no significan ningún cambio, ni accidental ni sustancial ${ }^{55}$.

${ }^{11}$ Cf. Báñez, D., In S. Th., I, q. 83, a. 1, col. 969D-E.970B.971C-972B.

52 "[...] illa enim indifferentia judicii optime dicitur a peritioribus Theologis radix libertatis, non tamen est ipsa formalis libertas" (Suárez, F., Opuscula, op. cit., I, cap. 2, n. 6, p. 10).

53 "Unde constat quam longe simus ab illa sententia quam Suarez putat nos tenere, quod ratio libertatis et usus illius consistat formaliter in cognitione et judicio indifferentiae objecti” (Báñez, D., Tractatus, I, cap. 3, n. 4, p. 372).

54 "In omni libero arbitrio creato invenitur non solum passiva indifferentia objecti cogniti ut indifferenter eligibile, sed etiam invenitur aliqua indifferentia passiva cum quadam potentialitate subjecti” (ibid., cap. 2, n. 6, p. 366).

55 Tal es la segunda conclusión defendida en este capítulo: cf. Báñez, D., Tractatus, I, cap. 2, n. 6, pp. 365-366. 
En definitiva, cierta indiferencia pasiva no obsta para el carácter libre de la criatura, antes por el contrario, la exige. Con todo, Báńez se expresa así en su cuarta conclusión: "La facultad del libre albedrío y el uso de dicha facultad, pese a ser un libre albedrío creado, no consiste formalmente en la pasión o en la potencialidad de esa facultad, sino que la facultad es verdaderamente activa y su uso es la acción" ${ }^{\prime 6}$. Frente a Suárez, que parecía haberle acusado de defender una indiferencia sólo pasiva, aquí Bánéz insiste en el carácter activo del libre albedrío. La definición del libre albedrío sostenida por nuestro teólogo implica que el libre albedrío posee libertad de ejercicio y de especificación, es decir, puede obrar o no obrar, hacer esto o lo otro. En consecuencia, "todas las acciones humanas, en tanto en ellas se encuentra la razón de bien o de mal moral, son verdaderas acciones elícitas realizadas por potencias activas, aunque, a causa del sujeto, tengan unida consigo algún tipo de pasividad, pues la potencia pasa de no obrar a obrar merced a la moción de un agente superior" ${ }^{57}$. La facultad finita de libre albedrío, por serlo, posee una potencialidad respecto de sí misma, en cuanto capaz de autodeterminación; pero también respecto del creador cuya moción no rivaliza con la propia automoción de la criatura.

Así, Báñez se siente en condiciones de afirmar que "Suárez trabaja en vano en el capítulo segundo del libro primero De auxiliis, cuando muestra que esta indiferencia del libre albedrío creado y el uso de su libertad no consiste en una pasión, pensando que define ahí algo en contra nuestra. En realidad, pretende vulnerar a un enemigo fingido por su propia imaginación" ${ }^{58}$. En efecto, la acusación de entender la voluntad creada de un modo meramente pasivo, que Suárez lanza contra los dominicos desde 1594, no está fundada, porque siempre habían afirmado que Dios mueve la voluntad y provoca que ésta sea semoviente, sin anular esa capacidad. Es más, por la gracia divina no se degenera la libertad humana sino que es más asimilada al libre albedrío divino y su inteligencia es iluminada de modo más hondo, de manera que se vuelve más libre aun. La influencia divina no enajena los elementos intrínsecos de la criatura, por los cuales el acto es, de suyo y por sus principios internos, libre. Por eso, advierte Báńez:

56 "Nihilominus facultas liberi arbitrii et usus illius facultatis, quantumlibet sit liberum arbitrium creatum, non consistit formaliter in passione aut potentialitate illius facultatis, sed revera facultas est activa et usus illius est actio" (Báńez, D., Tractatus, I, cap. 2, n. 6, p. 367).

57 "Et denique omnes actiones humanae in quibus dumtaxat invenitur ratio boni aut mali moralis, sunt verae actiones elicitas a potentiis activis, tametsi ex parte subjecti habeant conjunctum aliquid passibilitatis, dum potentia transit de non operante in operantem virtute motionis superioris agentis" (ídem).

58 "Ex quo sequitur quod frustra laborat Suarez lib. 1 De auxiliis, cap. 2, ostendens hanc indifferentiam liberi arbitrii creati et usus libertatis non consistere in passione, putans se contra nos aliquid definire. Sed profecto ipse finxit hostem quem feriret" (ídem). 
Para disolver los sofismas inoportunos, ha de ser tenido siempre en cuenta que todo aquello que proceda de algo extrínseco no destruye la formalidad de la libertad ni su uso formal, el cual consiste en la subordinación de la voluntad al conocimiento de la indiferencia de los medios respecto del fin; tal cosa no puede destruir el libre albedrío ni su ejercicio ${ }^{59}$.

La capacidad de elegir reside en el libre albedrío mismo, no en una relación de "no coacción" respecto de un principio extrínseco ${ }^{60}$. En efecto, según nuestro teólogo, "toda la razón formalísima del libre albedrío consiste en la facultad activa no determinada a un solo acto, sino poseyendo una indiferencia negativa abierta a actuar de cualquiera de dos maneras o a no actuar. Esta potestad y facultad reside, pues, en el entendimiento y en la voluntad. En el entendimiento de modo radical, en cuanto en él está el conocimiento de la indiferencia de los medios hacia el fin; en la voluntad, en cambio, está de modo formal, en cuanto facultad de elegir cualquiera de dos posibilidades que es propuesta con indiferencia por el entendimiento" ${ }^{61}$. En definitiva, Báńez responde a Suárez refrescando los argumentos que el jesuita había arrojado contra él: muestra que su posición no destruye la esencia misma del acto libre y la relación que Dios mantenga con el libre albedrío no modifica en modo alguno que aquél se siga comportando de acuerdo con su propia naturaleza.

\section{Conclusiones}

EN LA PRIMERA PARTE de nUeStras páginas, hemos visto cómo Báñez respondía a Suárez en 1594 ofreciéndonos los pilares principales de su exposición polémica de la libertad de arbitrio. Como ya había dicho en sus comentarios a la Prima pars, la raíz del libre albedrío se encuentra en el entendimiento pero la libertad se da

\footnotetext{
59 "Observandum igitur est semper ad dissolvenda importuna sophismata quod, quidquid adveniens ab extrinseco non destruit formalitatem libertatis neque usum formalem illius, qui consistit in subordinatione voluntatis ad cognitionem indifferentiae mediorum ad finem, non potest destruere liberum arbitrium neque exercitium illius" (ibid., cap. 3, n. 2, p. 370).

${ }^{60}$ En este mismo sentido: "[...] the will fulfills all the requirements for self-determination of its acts, despite the fact that God moves it in each case. God acts from the outside and He participates in the action as an extrinsic mover of the will” (Torrijos-Castrillejo, D., "Was Báñez a Bańecian?”, American Catholic Philosophical Quarterly, 94 [2020], p. 444).

61 "Tota igitur formalissima ratio liberi arbitrii consistit in facultate activa non determinata ad unum, sed indifferentiam negativam habens ad utrumlibet agendum vel non agendum. Est autem haec potestas et facultas in intellectu et voluntate. In intellectu quidem radicaliter, inquantum est in illo cognitio indifferentiae mediorum ad finem; in voluntate vero formaliter est facultas eligendi utrumlibet quod ab intellectu cum indifferentia proponitur" (Báñez, D., Tractatus, I, cap. 3, n. 4, pp. 371-372).
} 
formalmente en la voluntad. Esta radicalidad consiste en la advertencia intelectiva del carácter "indiferente" de los bienes finitos ante la voluntad. Si bien la libertad se halla formalmente en la inclinación de la voluntad que sigue al entendimiento, la apreciación de la indiferencia de los medios respecto del fin es lo principal para salvaguardar el carácter libre de la volición. En cambio, para Suárez, la indiferencia consiste en la "indeterminación" de la voluntad. Pero, si fuera así, resultaría complejo hablar de libertad en Dios, pues su voluntad es inmutable y siempre ha estado inclinada del mismo modo, incluso en sus elecciones contingentes: nunca se ha visto en un estado de indeterminación. De modo similar, parecería que la voluntad finita perdería su libertad una vez determinada a un acto, cuando, en realidad, el acto determinado por ella es el acto libre por excelencia. Por otra parte, puesto que nos situamos en el contexto de la disputa sobre la gracia divina y la libertad, Báñez tiene una palabra sobre la compatibilidad de ambas: la moción divina intervendría en el acto libre sin enturbiar dicha advertencia de la indiferencia de los medios para alcanzar el fin. Por eso, con independencia de la eficacia de la gracia, la libertad de la voluntad no sufriría merma alguna.

En el texto de 1600 Bánez se hace eco de las renovadas acusaciones de Suárez y muestra que la postura dominicana no se parece en nada a una indiferencia pasiva, ni tampoco reduce toda la indiferencia al carácter indiferente del objeto captado por el entendimiento. Sin duda, la raíz de la libertad reside en la apreciación de la indiferencia del objeto, no en la indeterminación del entendimiento o de la voluntad: por eso persiste la libertad incluso cuando ambos se han autodeterminado a querer algo. No obstante, en la criatura también hay cierta indeterminación por cuanto es pasiva respecto de la propia actividad pero no menos respecto de Dios. Pero Dios no interviene como un extrańo sino que, en cuanto creador, al mover a la criatura se encuentra — por así decir — en casa propia.

Comenzamos nuestro artículo recordando que Báñez, además de ser famoso por su contribución al debate sobre la libertad y la gracia, también lo es por haber asistido de cerca a santa Teresa de Jesús. Pues bien, son de su "hija espiritual" estas palabras:

Él viva, y me dé vida; Él reine y sea yo cautiva, que no quiere mi alma otra libertad. ¿Cómo será libre el que del Sumo estuviere ajeno? [...] Dichosos los que con fuertes grillos y cadenas de los beneficios de la misericordia de Dios se vieren presos e inhabilitados para ser poderosos para soltarse. [...] ¡ Oh, libre albedrío, tan esclavo de tu libertad, si no vives enclavado con el temor y el amor de quien te crió! ${ }^{62}$.

${ }_{62}$ Teresa de Jesús, "Exclamaciones", 17, nn. 3.6, en Obras completas, Efrén de la Madre de Dios; Steggink, Otger (eds.), Madrid, BAC, 2006, p. 648. 
La experiencia mística de la Santa no ve la influencia de Dios sobre su libertad como la injerencia de un poder hostil, arbitrario o avasallador - como podría sospechar el hombre moderno-. Por el contrario, declara que el libre albedrío no pierde tanto su libertad sino cuando se determina al margen de Dios. Antes hemos leído unas líneas de Báñez dignas del confesor de Teresa: "[...] cuando el ímpetu de nuestra voluntad es guiado y llevado del ímpetu del espíritu de Dios amorosamente, no por eso deja de ir con perfecta libertad [...], antes va caminando con miedo de que es posible cesar del amor de Dios o faltar a su ley por la potestad que en sí siente antes de conseguir el último fin, que es ver a Dios. Donde ya la voluntad no quedará con libertad para poder dejar de amar a Dios, porque la vista clara de Dios le descubre estar en Él todos los bienes juntos en un sumo y infinito bien, y así ya no puede tener aquel juicio de que le puede convenir querer algún bien fuera de Dios. Pero aun entonces queda libre para amar a las criaturas [...] enderezando este amor a Dios" ${ }^{63}$. Este encaminarse a Dios como el bien más propio del ser humano que quepa pensar no suponía, para estos cristianos del siglo XVI, una enajenación de la vida terrena. Es de sobra conocida la apuesta de Teresa por la vida activa y el sincero empeño en las faenas cotidianas, inclusive las más humildes ${ }^{64}$. Con ello, no se apartaba demasiado del espíritu de la Escuela de Salamanca cuyos doctores, mientras discutían abstrusas cuestiones de teología, no olvidaban los problemas sociales de España y América. Tal es el talante que también luce Báñez, cuyo verdadero rostro esperamos haber contribuido a mostrar.

\footnotetext{
63 Báńez, D., Respuesta, p. 456.

${ }^{64}$ Cf. Teresa de Jesús, "Meditaciones sobre los Cantares", cap. 7, n. 3, en Obras completas, op. cit., p. 465; "Séptimas moradas”, cap. 4, n. 14, ibid., p. 581; “Camino de perfección”, cap. 17, nn. 5-6 Valladolid; cap. 28 , nn. 5-6 El Escorial, ibid., pp. 304-305.
} 


\section{REFERENCIAS BibLIOGRÁFICAS}

Almainus, J., Moralia, Paris, Gaudoul, 1516.

Báńez, D., Scholastica Commentaria in Primam Partem Angelici Doctoris D. Thomae Aquinatis usque ad sexagesimam quartam Quaestionem complectentia, Romae, J. Ruffinellus, 1584.

Bánez, D., Super Primam Partem divi Thomae à Quaestione Sexagesimaquinta usque in finem Commentariorum, Salmanticae, S. Stephanus, 1588.

Báñez, D., Comentarios inéditos a la Prima secundae de santo Tomás, Beltrán de Heredia, V. (ed.), vol. 3, Madrid, CSIC, 1948.

Bánez, D., Apología de los hermanos dominicos contra la Concordia de Luis de Molina, Hevia Echevarría, J. A. (trad., introducción y notas), Oviedo, Pentalfa, 2002.

Bánez, D., Tratado sobre el hombre. Comentario a Suma Teológica, I, qq. 80-83, García Cuadrado, J. Á. (introducción y notas); Gallego Salvadores, J. J.; García Cuadrado, J. Á. (trad.), vol. 3, Pamplona, EUNSA, 2015.

Bellarminus, R., Controversia de gratia et libero arbitrio, vol. 5, Opera omnia, Paris, Vivès, 1873.

Beltrán de Heredia, V., Domingo Báñez y las controversias sobre la gracia: Textos y documentos, Madrid, CSIC, 1968.

Beltrán de Heredia, V., "Valor doctrinal de las lecturas de Báñez", en Miscelánea Beltrán de Heredia, vol. 3, Salamanca, OPE, 1972, pp. 141-166.

Cai, Y., "The Efficacy of Grace according to Domingo Bañez", Augustiniana, 62 (2012), pp. 291-326.

Craig, W. L., The Problem of Divine Foreknowledge and Future Contingents from Aristotle to Suarez, Leiden, Brill, 1988. doi: 10.1163/9789004246560

García Cuadrado, J. Á., Domingo Báñez (1528-1604): Introducción a su obra filosófica y teológica, Pamplona, Servicio de Publicaciones de la Universidad de Navarra, 1999.

Hasker, W., Providence, Evil and the Openness of God, London/New York, Routledge, 2004.

Matava, R. J., Divine Causality and Human Free Choice. Domingo Báñez, Physical Premotion and the Controversy De Auxiliis revisited, Boston, Brill, 2016. doi: $10.1163 / 9789004310315$ 
Matava, R. J., "A Sketch of the Controversy de auxiliis", Journal of Jesuit Studies, 7 (2020), pp. 417-446. doi: 10.1163/22141332-00703004

Mateo-Seco, L. F., "Providencia y libertad en D. Báñez", en González-Ayesta, C. (ed.), El alma humana: esencia y destino. IV Centenario de Domingo Bánez (15281604), Pamplona, EUNSA, 2006, pp. 171-192.

Molina, L., Liberi arbitrii cum gratiae donis, divina praescientia, providentia, praedestinatione et reprobatione concordia, Olyssipone, Riberius, 1588.

Osborne, Th. M., "Thomist Premotion and Contemporary Philosophy of Religion", Nova et Vetera, English Edition, 4 (2006), pp. 607-632.

Scorraille, R. de, El P. Francisco Suárez, de la Compañia de Jesús, Barcelona, Subirana, 1917.

Serry, J. J. [Le Blanc, A.], Historiae congregationum de auxiliis divinae gratiae, sub Summis Pontificibus Clemente VIII et Paulo V, Lovanii, Aegidium Denique, 1700 .

Solana, M., Historia de la filosofía española. Época del Renacimiento. (siglo XVI), vol. 3, Madrid, Asociación Española para el Progreso de las Ciencias, 1940.

Soto, D., De natura et gratia, Venetiis, Iuntas, 1547.

Suárez, F., Opuscula, vol. 11, Opera omnia, Paris, Vivès, 1858.

Teresa de Jesús, Obras completas, Efrén de la Madre de Dios; Steggink, Otger (eds.), Madrid, BAC, 2006.

Torrijos Castrillejo, D., "Tomás de Vío, Cayetano: Sobre la providencia y el hado", Revista española de teologia, 78 (2018), pp. 459-500.

Torrijos Castrillejo, D., "Was Báñez a Bañecian?”, American Catholic Philosophical Quarterly, 94 (2020), pp. 431-458. doi: 10.5840/acpq2020943204

DOI: https://doi.org/10.15366/bp2021.26.009

Bajo Palabra. II Época. No26. Pgs: 179-200 
